\title{
Seeing is Believing: A Case Study of Interdisciplinary, Experiential Science Education
}

\author{
Saswati Majumdar, Ed.D. (Corresponding author) \\ School of Education, University of Louisiana at Monroe \\ 700 University Avenue, Monroe, LA- 71209, USA \\ E-mail: majumdar@ulm.edu
}

Received: March 10, 2018 Accepted: April 18, 2018 Published: May 1, 2018

doi:10.5296/jse.v8i2.12888 URL: https://doi.org/10.5296/jse.v8i2.12888

\begin{abstract}
Situated in a rural, impoverished town in Northeast Louisiana, this case study takes a deep look into two highly effective teachers' pedagogical practices along with the concomitant patterns in attitudes towards scientific literacy among their students, as well as the role of the emergent curriculum in the process. It explored nuances of a unique approach to bring in interdisciplinary science through the backdoor, since science received little importance in the context of the school as well as community. Using qualitative measures, the study examined the teachers' pedagogical practices and students' attitudes towards science as well as subtle, everyday interactions involving the discourse of science and the resulting, emergent curriculum surrounding an innovative, teacher-designed intervention. Qualitative findings showed that the emergent curricular models in different teachers' classrooms shaped the outcomes. Classroom interactions surrounding the intervention vis a vis the emergent curricula encompassed an open, dialogic and interactive discourse closer to a post-modern approach, where both teachers and students seemed to excel and together shaped a rich, recursive, relational, and rigorous process of learning and integration of the intervention, within a small creative window situated in a transitional context of K-12 education.
\end{abstract}

Keywords: experiential education, instrumental case study, interdisciplinary, scientific literacy, post-modern curriculum 


\section{Introduction}

The environment provides an integrating context for learning science (Sobel, 2008). The value of a discourse rooted in the local context, is found when students recognize they can use their minds and energy to contribute to, as well as learn from, the communities in which they live. Science education using the environment provides a meaningful context for learning and a source of communal connection (Sobel, 2008). The innovation built into approaches that bring students in contact with real-life, locally rooted sources of learning and stretches the classroom beyond the four walls, have been associated with regenerating students' interest in education as well as energizing teachers (Knapp, 2008). This form of pedagogy uses natural and sociocultural environments as the context for learning, and builds on best practices that are often free from traditional boundaries separating disciplines. It creates opportunities for hands-on learning experiences, helps develop team-teaching, adapts to individual students and their unique abilities, and inculcates understanding and respect for Science and the environment (Lieberman \& Hoody, 1998).

Research has shown that students' level of interest in science is impacted by prior knowledge and connections of science-related topics to their daily lives. Innovative learning (creative thought process integrating simple ideas to build/solve complex ideas) allows both students and adults the opportunity for intrinsically motivated, lifelong, and self-controlled learning, which is a more effective means of learning and retention than just the traditional classroom-based curriculum (Falk, 2002; Falk \& Dierking, 2002; NSF, 1998). In other words, learners are more likely to learn meaningfully and retain content when they build on their own experiences.

In this study, two teachers from two different disciplines of English Language Arts (ELA) and Science surmounted various challenges to develop ways to integrate an interdisciplinary intervention as part of a University-schools' partnership at a middle school situated within a rural, farming community. The classroom intervention itself consisted of a teacher-designed unit in Science, with interdisciplinary connections in ELA. The components of the intervention included the experiential processes of scientific inquiry, data collection, building experiences with the content and developing interactions and dialogue surrounding the content. In essence, the intervention was a way to connect learners with their surrounding realities and integrating the learning experience with their comprehensive curriculum.

\section{Literature Review}

\subsection{Scientific literacy}

Scientific literacy is defined in this study as a functional understanding of concepts where students construct a personal meaning of the content and their interdisciplinary connections in reality, as opposed to abstract, text-based knowledge (Doll, 1993; Roth \& Calabrese Barton, 2004). The National Science Foundation (NSF) emphasizes that balancing formal (traditional) and informal experiences optimize student motivation and boost performance significantly. It contends that scientific discoveries should be presented in ways not only understandable, but also enjoyable through self-directed, voluntary explorations, that inculcate critical thinking, 
thus building scientific literacy. Such approaches break away from a traditional, factory-like, system of schooling science and enacting curricula characterized by the rigid passage of facts, from teachers to students assumed to be empty vessels (Friere, 1970).

Research suggests that a sense of personal relevance is necessary for learners to pay attention, and give importance to learning science, which also includes the 'how' and 'why' of learning science (Falk \& Coulson, 2002). In this study, a particular characteristic is the way in which the content is framed connecting learners with the realities surrounding them, while linked with the comprehensive curriculum. Scientific literacy in this case became participatory, aligned with citizen science which is collective and situated in the context. For instance, students assessing patterns of the weather through seasons, plotting the data and analyzing it, as well as communicating about the process reflexively, while in touch with the comprehensive curricular framework, rather than following it inflexibly is both participatory and situated. This approach also meets the demands of the need for STEM education in the current global scenario as well as the United States' average and below average performance on international platforms (Organisation for Economic Cooperation and Development, 2015).

\subsection{Experiential education}

Researchers such as Duran, Hepburn, Irvine, Kaufmann, Anthony, Horen, \& Perry (2009) pointed out that during an era dominated by standardized education, developing inquiry-based, experiential approaches to learning science is a small window wherein lies the possibility of challenges as well as wonder and excitement that motivate both teachers and students. The significance of such a practice of learning science goes beyond mere excitement. McCarthy (2005) found that instructional methods involving hands-on science made significant improvements in diverse students, such as students with special needs. This approach is congruent with what Dewey (1915) wrote one hundred years ago, "In critical moments we all realize that the only discipline that stands by us, the only training that becomes intuition, is that...........we learn from experience (p.15)". Dewey believed in the transforming power of experiential education in both the child's life and in renewing a school.

Often schools are places of conformity where the top-down prescription for content and sequence is followed with little to no flexibility in the classroom. Experiential education challenges this notion through a path for students to construct meanings of concepts personally which permanently become part of their learned schema. Context plays a huge role in helping students construct meaning, nurture positive attitudes and motivation towards learning science, and develop an understanding of the nature of science/scientific literacy. Informal learning experiences can be incorporated into curricula through inquiry-based approaches towards connecting standardized/prescribed curriculum and the real world outside the classroom (Freedman, 1997; Parker \& Gerber, 2000; Ricks, 2006; Romance \& Vitale, 2001). Jean Piaget (1954) included the experiential perspective within his theory of constructivism calling the interaction of students' experiences and their ideas in the generation of knowledge where students can use their prior knowledge and try to connect to the newly given knowledge and form connections to the experience. However, the outcome 
of such an effort may not always be a final product, but rather a way to help students synthesize concepts and understandings. Through experiential learning, a student can deconstruct problems using their previous experiences while simultaneously constructing new concepts in the process.

\subsection{Place-based education}

Place-based education (PBE) is an educational approach that is place-conscious and situates curriculum within a local framework. Innovative in nature, it begins with the effort to learn how local events relate to regional, national, even global forces and events, producing new understanding of content in real life through an engaging curriculum, generating conscious ecological stewardship (Sobel, 2005). Here in Louisiana, Caldwell Middle School in Terrebonne Parish, through its $4 \mathrm{H}$ Club, has been successfully running a mosquito control project. Louisiana is mosquito infested, but students wanted to fight it without harmful pesticides. Through a student-led, inquiry based project, they have successfully used the native mosquito fish to control the mosquito population (Sobel, 2004).

PBE involves students locally in issues, oftentimes countering the effects of multinational businesses and push for globalization at the cost of unique, smaller and vulnerable local communities (Gruenewald \& Smith, 2008). In science education, place-based learning and instruction has tremendous potential in engaging underrepresented learners through situated scientific inquiry (Lim \& Calabrese-Barton, 2006). By developing a sense of place, PBE helps students connect with their land, natural and cultural resources, thereby arming them with knowledge, and aesthetics of caring to transform their environment/community. It helps young people connect with various aspects of locality through "real work" and take home a vital experience and personal sense of identity that translates to empowerment and engagement (Sobel, 2008).

Since PBE embodies a conscious approach, (e.g., being conscious of one's immediate environment, learning from it, and contributing to it with knowledge and understanding gained), the discourse is also comparable to critical pedagogy (Gruenewald, 2003). An interesting aspect in educational research literature shows the complementary foci/coverage of PBE underscoring the importance of mainly rural environments and critical pedagogy, which translates to reclamation of the land (McLaren \& Giroux, 1990). Paulo Friere (1970) coined the term "critical pedagogy" which begins with the conscious recognition that humans and all institutions (including schools) within a cultural context have spatial, geographical and cultural dimensions. Friere envisioned a conscious, interactive and problem-posing education where learning progresses through students' questioning. PBE creates the conditions for both generating curiosity and by allowing students to relate to the topic, and engaging them through hands-on learning and dialogue that impacts their daily lives.

\subsection{Citizen science}

A compelling approach that incorporates critical PBE, in a post-modern way into the science curriculum is citizen science (CS). CS, the latest iteration of participatory science seeks to answer research questions collaboratively that are impossible to answer by scientists, working 
individually (Miller-Rushing, Primack, \& Bonney, 2012). CS involves people from all walks of life and has historical roots in ordinary citizens investigating scientific questions through their observations, recordings and interpretations.

CS has carved out two principal areas in learning/dissemination of science. First, it feeds into investigating answers for ecological (thus environmental and humanitarian) questions at scales achievable only through involvement of large number of stakeholders. The scales of operation are both local and regional, such as water monitoring, or wildlife monitoring datasets. Second, it pays attention to scientific niches that are usually not professional scientists' focus of research. Example, investigating small, local environmental problems, and finding localized sources of pollution, wildlife deaths, etc., fall within its purview. Such studies may lead to policy changes that impact the local environment (Miller-Rushing, Primack, \& Bonney, 2012).

\subsection{Post-modern approach}

The relevance of a post-modern approach within the context of a classroom lies in its potential to break away from the isolating norm of abstraction in learning towards remotely decided, predetermined outcomes. For the past half-century, educators and curriculum researchers have pointed out the failure of the formal curriculum and initiated a reconceptualized vision of curriculum, comprised of self-reflection, and conscious learning through experience (Pinar, 1975). The meaning of curriculum thus interpreted signifies a dynamic discourse that is a conscious and personally relevant journey for each student. Notably, this dynamic and flexible form of curricular thinking is aligned with experiential, empowered, student-centered learning, represented by PBE and postmodernism (Dewey, 1929; Esteva \& Prakash, 1998).

Postmodernism brings together all the above themes of learning within its philosophical foundations. It is a process-oriented approach to curriculum and a way of learning that embraces openness and constructivist epistemology where both teachers and students as co-learners engage in learning through rich and ongoing conversations to seek meaning of the content (Doll, 1993). Transforming the conventional separation of content, the post-modern curricular framework attempts to integrate complex cross-curricular understandings marked by richness, relations, recursions, and rigor (Doll, 1993). Richness refers to interpretation of content through multiple perspectives, enriched by cumulative understanding of individual learners. Relations refers to connections in terms of learners interpreting the content at a personal level while also incorporating the physical (contextual) aspect of their realities (place-based). Recursion is not repetition but rather reflection on learning that renders depth and gradually increases accuracy and perfection. For example, daily reflection after scientific investigation is routine practice in field-biology that not only points out the nature of successes and flaws in one's approach but also facilitates in developing a metacognitive framework that guides the learner. Finally, rigor transcends a traditional definition of difficulty to include indeterminacy which allows alternative conceptualization of the content, attaining increasing complexity through interaction and dialogue and producing results that are personally relevant within a network of knowledge. 
Therefore, different parts (disciplines) in the curriculum ought to be connected, rather than isolated into boxes, which in turn are connected to the learner, thereby making learning a complex and dynamic activity (Doll, 1993). Scholars have noted important challenges to be overcome, since a majority of everyday educational practices are still ingrained with inflexibility of modernity. Unfortunately, many schools are focused on standardized testing and maintaining rigid disciplinary boundaries, holding teachers accountable for all students' standardized test scores in their subject areas. Betts (1992) coined the term "paradigm paralysis" (p. 38) to refer to the current state of American education, wherein even under a label of change the status quo continues. Countering this, post-modern scholars like William Doll (1993), opine that knowledge equates to freedom of exploration- that is, to open up new dimensions. This is an open vision of learning, close to an ecological perspective and cosmology that sees self and realities in a relative way. An open, biologically-oriented model that sees humans and their learning processes allied with self-organizing, living systems that "interact", as opposed to a simplistic, logical and positivistic, non-quantum view where everything is predictable and like clockwork aligns with predetermined curriculum that is inflexible and presents knowledge as uncontested facts with little room for growth and personalization for students.

\section{Research questions}

Using the curricular framework of postmodernism, the researcher conceptualized a theoretical lens comprised of the experiential learning approaches of CS and PBE with an aim of examining the nuances of the discourse of scientific literacy surrounding the intervention.

RQ1. With regard to the discourse of learning science surrounding an innovation, what were the characteristics of- a) teachers' pedagogy? b) students' approach to developing scientific literacy?

RQ2. What were the characteristics of the emergent curricular model?

\section{Conceptual framework}

In this case study, a conceptual framework was used to examine classroom practices surrounding an intervention, investigating areas of intersection between post-modernity and experiential education, classroom practice, and the role teachers and students play in generating curriculum. Pinar (1976) defined a reconceptualized curriculum in the post-modern light as comprised of self-reflection (autobiography) and conscious experience (phenomenological experience), which translates to be able to see oneself in the process of learning. Accordingly, the study included attempts to situate how (emphasizing the process) an intervention interacted with teachers' conceptualization of content and pedagogy, and students' interactions with the content and their processes of learning, and how that leads to generation of a transformative curriculum (breaking away from the traditional and unquestioned) which leads to scientific literacy. The mode of learning was framed in the study in terms of how students can construct their own meaning, with their experiences through the hands-on approach used in the intervention. The experiential approaches of PBE and CS were situated under the umbrella of postmodernism. The process of acquiring 
scientific literacy was thus conceptualized as residing within a non-traditional framework that is open in nature, since the post-modern approach examines any learning event with an open, interactional framework. Thus, PBE was examined within the scope of post-modern science, and CS was treated as a vehicle for imparting scientific literacy in the middle school classroom. The specific classroom intervention consisted of a teacher-designed unit in Science, with interdisciplinary connections that were developed as part of a university/school partnership. The common tenets of the intervention included processes at the heart of PBE and CS: scientific inquiry, data collection, building experiences with the content and interactions and dialogue surrounding the content.

\section{Context}

As part of the contemporary backdrop, there is tension and anxiety among teachers for the amount of content to be covered and the time required. In this study one of the teachers, Ms. AM in addition to teaching ELA, was also a Special Education teacher. As mentioned earlier, researchers have repeatedly found that instructional methods involving hands-on science make significant difference in students with diverse needs. Thus, this approach was especially significant for some of her ELA students who were also in Ms. TD's Science class, and had accommodations. Although time consuming, hands-on, inquiry based learning and authentic experiences add to the learning outcomes beyond test scores (Wyss, Dolenc, Kong, \& Tai, 2013). While both collaborating teachers readily immersed themselves into the process of integrating this intervention instructionally, there were significant challenges faced in terms of the prescribed curriculum as well as resistance from the administration.

Since innovation in experiential learning encompasses active, inquiry-oriented approaches, and is still used as an alternative curricular approach, it can be labor intensive. Apart from adopting a new system of instruction and assessment, teachers often have great difficulty in making a paradigm shift in becoming more of the facilitator and shifting from a conventional leadership role (Goodnough \& Cashion, 2006; Wyss, Dolenc, Kong, \& Tai, 2013). Resources to support this shift include local university faculty and researchers. As such, the role of the university partnership is thus significant in setting the stage for change.

The introduction of Common Core State Standards (CCSS) and Next Generation Science Standards (NGSS) into classrooms has led to the need for adopting new ways of teaching, learning, and re-conceptualizing the content, within a post-modern curriculum (NGA, 2008). During this period of transition, professional development of teachers is critical. Research shows that not only students' but teachers' beliefs in self-efficacy and inquiry-based learning have been powerfully impacted by professional development programs that underscore the importance of innovation in learning and instruction (Webster-Wright, 2009). Duran, Hepburn, Irvine, Kaufmann, Anthony, Horen, \& Perry (2009) noted that the integration of informal, innovative science education can be a catalyst for students and teachers to gain unique and memorable learning experiences that stretch far beyond the walls of the traditional classroom. As McComas (2006) highlighted, the experiences need to be designed carefully and cognitive connections made to the curriculum. As schools are transitioning from the No Child Left Behind standards to the NGSS and CCSS framework in science 
education, there is tremendous need for professional development that supports curriculum development. Current educational policy developments in Louisiana and at the national level have led to several unintended consequences that have the potential to make teaching and learning stressful in K-12 classrooms. For instance, two other collaborating teachers left the study unexpectedly since they could not balance the pressure of implementing the scripted curriculum along with the innovation. Thus, teacher attrition was a fallout of this context. Also, recent teacher evaluation policy (Compass) has tied student performance to teachers' recognition, remuneration, and professional security (Firestone, 2014) which adds to the sense of insecurity for many teachers. In this high-stakes accountability atmosphere, lack of trust pervades professional relationships and that of students' relationships with teachers (Booher-Jennings, 2005).

For instance, the administration's approach to the innovation was not very supportive, likely as a function of the risks perceived from straying from the prescribed curriculum as well as giving less importance to science. This is what the teachers in this study had to work through and surmounted successfully in order to bring fresh perspective on the content, surrounding this innovation. Walking into the school, the first day, the researcher was greeted by office staff, an elderly lady with a Southern accent and characteristic warmth of people from this region. She guided the way to the class, but hesitated to allow the researcher in; the classroom door was locked from within. The lady asked the teacher if she was indeed expecting a visitor, to which the teacher conceded. Finally, the researcher was ushered into the class. Also, there was no opportunity to speak with the Principal. It is worth mentioning here that the researcher had explicit permission to document the project at the school site. However, the Principal seemed not too keen for Ms. TD (the Science teacher) to take students out to the field, where the weather station was. She rebuked the teacher when students tracked in dirt, and made little eye contact with the students, showing some form of dissent on an occasion of field trip. Being witness to such interaction/s favored the impression that the Principal did not find it necessary or helpful for Science teachers to do field work regularly; something that the administration could not directly control, as opposed to classwork. Feedback discussion with the teacher revealed that the Principal did not find field trips very important and was in favor of classroom study instead. There seemed a disconnect between the Principal's background in ELA and that of the Science teacher's. The unique importance of field work in Science is understood and shared knowledge among Science teachers. Overall, the school also seemed to lack resources/funding. There were multiple areas that needed attention, such as the library that had recently lost its only librarian due to budgetary constraints, and classrooms did not have too many resources. However, one of the positive aspects about the site was that the small size of the school seemed to generate warmth and closeness among teachers, where all teachers seemed to address one another by first name and shared workspace, as in a small community, although there seemed to be uptightness with visitors, especially felt by the researcher, as a foreigner. 


\section{Method}

\subsection{Approach}

After formulating research questions and forming a conceptual framework, necessary contacts were established with the field-site, and permissions obtained for the study, including approval of the Institutional Review Board (IRB). Students in the selected teachers' classrooms had the opportunity to participate with parental permission. Site visits were initiated with an exploratory tour of the site. Detailed classroom observations, teacher interviews, and student focus-group discussions were carried out thereafter to uncover fine details of students' and teachers' classroom interactions with the content, and among themselves, which were also utilized to reconstruct the curricular model(s) operating in the classrooms. Teachers were also contacted for a follow-up discussion, to wrap up the work through participant validation. These multiple layers of data collected over a period of three months, lent depth and richness to the study that was essential in understanding the nuances of the classroom (Miles, 1994). Data collection was followed by analysis and interpretation. As Van Manen (1997) suggested, the qualitative aspect of a study is interpretive in nature, or well suited to finding or making meaning out of events or processes, with respect to people's perceptions or assumptions as well as value judgments.

\subsection{Setting}

Louisiana has the second-highest poverty rate in the United States, with $17.6 \%$ of its population falling below the poverty line, with concentrations in some rural areas that include the site in this study (U.S. Census Bureau, 2010). The school in this study was categorized as high-need by the state, with an average of $80 \%$ of the students qualifying for free-and-reduced lunch in addition to a high percentage from minority backgrounds.

\subsection{Participants}

Participants for this study were drawn from a school site that partnered with a University in Northeast Louisiana through a professional development program, although this study was independent from the program itself. At the school site, there was a leading science teacher, and a few collaborating teachers in other content areas. The current study was preceded by two professional development programs (phases I \& II) where area middle schools collaborated with the university. Guided by a framework developed during the second phase, the selected school was categorized as a high-implementing site, based on the pattern of classroom implementation, workshops attended by teachers, process/quality of student data collection, and follow-up discussions. These teachers were part of the prior first and second phases of the partnership program, and were now part of the third phase as well. The student focus groups were decided upon jointly by the teacher and the researcher. The researcher intended to study a mix of high and low performers in class, but ended up with a mix of more responsive and higher performing students, upon recommendation of the teacher. To protect the participant's privacy, names of institutions and individuals were not used. 


\subsection{The intervention}

The Physical and Earth Science teacher led and collaborated with the ELA teacher and planned a multidisciplinary unit.

- Physical Science- Students did an ongoing investigation by collecting data from the weather station in the school backyard, located in a local agricultural field. They also set up and retrieved samples of local fauna using pitfall traps.

- Students did an in-depth examination of the data, plotted into graphs through the season (showing patterns of rainfall, temperature, UV index, evaporation, and humidity).

- Students also analyzed newspaper articles on current and past climatic conditions, agriculture and economy, and wrote short essays.

- $\quad$ ELA- Students prepared a weather report and made a detailed news presentation (in pairs) on various climate related natural disasters. In the process, they prepared a write up, collaborated on rehearsals, and staged an actual performance, replete with reading, writing and articulation skills.

\subsection{Classroom implementation of the intervention}

The school site had a team of two collaborating teachers, Ms. TD, the Earth and Physical Science teacher, and Ms. AM, the ELA and Special Education teacher. There were two other teachers initially in the team from Math and Social Studies. However, the Math teacher dropped from the program as she shifted from middle school to elementary school blaming the workload; the Social Studies teacher was unwilling to participate in the collaborative work given the pressure of the changes in the state curriculum.

The intervention was carried out in Ms. TD's $8^{\text {th }}$ grade Earth Science class of over 20 students. It consisted of a combination of students collecting data and discussing/analyzing it, as well as maintaining a weather station in the school backyard, along with setting up and retrieving samples of local fauna from pitfall traps. This was carried out as an ongoing field-work between mid-February and mid-April, with weekly follow-ups. Between February and mid-May, teacher interviews (pre- and post) and ad hoc student focus-group discussions were carried out with a few students (3) that have been identified in the study as focus-group participants.

The intervention was carried out simultaneously, although in lesser frequency in Ms. AM's $8^{\text {th }}$ grade ELA class. In this class, students prepared a weather report, and made detailed news presentations (in pairs) on climate-related natural disasters. In the process of designing their presentations, students composed their script drawing on their experiences, collaborated on rehearsals, and staged an actual performance, replete with reading, writing and articulation.

\subsection{Qualitative Analysis}

All teacher interviews were recorded using voice recording software RCA Digital Voice Manager, with permission from participants. Teacher interviews and student focus group discussions were transcribed into MS Word document and uploaded into ATLAS.ti (Version 
7.5.3) as primary documents. All transcripts were read by the researcher, and categorized into emergent codes, applying the theoretical framework consisting of post-modern perspective of curriculum, experiential learning, citizen science, and place-based education. Using emergent codes from qualitative analysis, the most prominent code families were identified and examined. Results were compiled by research questions and meanings were interpreted.

\section{Findings}

\subsection{Study site}

School site H was classified as a small-sized, Title-I school. Drawing evidence from the teacher interviews, it had a majority of Caucasian students, followed by minority of African Americans, and very few Asian Americans. The school was located in a rural district of Northeast Louisiana, within a predominantly agricultural, low income settlement.

7.2 RQ1a: With regard to the discourse of learning science surrounding an innovation, what were the characteristics of: a) students' approach to developing scientific literacy? b) teachers' pedagogy?

Evidence from the teacher interviews and observations suggest that there was great enthusiasm between both teachers and a large majority of their students, towards the intervention, at this site. Ms.TD noted that there was a steadily growing affinity, regular activity and critical thinking surrounding the intervention.

TD: “...you cannot tell how and where it (the intervention) is gonna (going to) help you in life. You have to know how to use it."

The intervention seemed highly valued by teachers and students, and viewed as a versatile resource. After implementing the intervention regularly with her students, between mid-February and April, TD noted that:

TD: "It (the intervention) is crazy useful. We are a farming community. So, temperature has to do with farming, humidity has to do with it. Air pressure, for example - if you know the air pressure, you can tell if a storm is coming. So, there are all those connections. And, the students love being outside."

Evidently, TD readily connected the intervention with that of the local needs. Although she did not live in that area, her use of the word 'we' is notable. It conveys a sense of fellow feeling towards the community. She noted that the local farming community was in perpetual need to know about weather variables such as temperature and relative humidity, both of which are in direct relation with watering and maintaining crops; air pressure which could predict stormy or calm weather. Therefore, students coming from this community should be able to see the importance of an intervention that teaches them how to read and predict weather conditions. In addition, middle school students like being active and outside of the classroom when given an opportunity.

TD: “...at the age where they are (generally) not confident about what they do. And now, they can walk out with the tools...record it and they got it! And then, when the parents come 
around they're ready to show their parents that they are on top of the class, because they can do these things."

TD's affirmation of students' fascination towards the intervention is notable. This, in itself indicates a positive attitudinal shift in students. Beyond virtually stretching the classroom into the field, the intervention seems to have gone further for the students to be able to make critical as well as personal connections. So, students made connections to the day-to-day realities of the area, and had a boost in self-esteem, both of which represent a positive approach towards the intervention and learning science in general. TD also brought finer nuances about the relationship of science with the community from which the students came. She mentioned that while there is positive acceptance towards doing exciting activities in science, the importance of science in the region is dampened by an apparent sense of contradiction of prejudices and beliefs expressed by some students' parents/family members on certain topics.

TD: "Yes, the community's perspective on Science does affect student's attitude towards Science. One student specifically, he did not even want to do a test on say, global warming, because he did not believe in it (smiles). Because grandpa did not believe in it..."

Although in the above quotation TD highlighted one student's dilemma between science and family beliefs, this is not an isolated incidence. Many researchers have noted that an authoritarian culture, as exemplified above, supported by policies tinged by political interests can be a major deterrent for students being able to open up to new knowledge and understandings in science (Branch, 2013). However, drawing on evidence from teacher interviews, corroborated by observations, students' attitude and responses emerged as a strong factor at this site. TD also emphasized the good relationship she shared with students and their positive responses in class.

TD: "I want them to take ownership of what they do. So, if majority picked to do it, you wanted to do it! So, then they own it!"

TD discussed the way students took ownership of the intervention. In multiple studies involving place-based education, or curricula with a local focus, students have been found not only to achieve better in classroom assessments, but show significantly higher attitude scores for pastoralism or enjoyed nature with an intellectual understanding, and simultaneously lower scores for human dominance using technology over nature (Education Development Center, 2000).

Ms. AM, the ELA teacher also had a positive view of students' responses, as noted below.

AM: "And, they felt like a group, rather than individuals in a class. They worked as a group to do the whole thing."

AM valued the collaborative approach of the intervention, not only among teachers across content areas, but also the camaraderie and collaborative learning environment it created for students. The integrative view of curriculum emphasizes the process of learning and building a collaborative environment, as opposed to desolation created by competitive forces of a 
modern curriculum (Slattery, 2006).

Focus group discussions

The researcher had discussions with focus-group students as well. On asking if the intervention was helpful, student A thought that there were multiple ways in which the intervention helped her- firstly, understanding the weather was significant since it consisted of quite a few complex and interconnected concepts such as, being able to make naked eye observations and using the weather station instruments accurately (scientific inquiry, Physical Science), making sense of the variables (Earth Science), being able to detect the trends in the data (Math) and so on. Therefore, she believed that the experience helped her progress in multiple content areas. Student $M$ thought the instruments were interesting and life-saving as well. He loved to study the instruments. These responses signify the multiple perspectives of interpretation of students towards the intervention and developing scientific literacy.

7.3 RQ1b. With regard to the discourse of learning science surrounding an innovation, what were the characteristics of: b) teachers' pedagogy?

Ms. TD's approach in facilitating and framing the intervention is summarized in the following quotation.

TD: “...even though the time went down, the intensity went up."

As part of the learning process associated with the intervention, TD arranged a short field-trip (with the Principal's permission) to the school field. TD had apparently undergone a long struggle all the way to appealing with the Human Resources, just to gain permission to put up the instruments. On the contrary, a field trip was a very rewarding experience for students who were eager to do so. Drawing on informal discussion with the teacher, due to various constraints, mainly disciplinary stipulations by the Principal, and extreme pressure, limited time in preparation for standardized testing, the effective time for field-trips was greatly reduced. However, although time was reduced from 30 to about 15 minutes, students seemed more focused and the opportunity for field work became more prized. As a result, more data was collected in half the time, compared to earlier, longer sessions. Evidently, the teacher played an important role in enhancing the importance students attach to science.

The following statement by Ms. AM represents a shift towards a positive acceptance of the intervention as something beneficial, as opposed to yet another activity to complete.

AM: "In the beginning, I was not so sure this was going to work. But, you know it really worked.”

Planning and implementing a unit built around science was something new, and it took some adjustment for AM. Teachers were apparently more familiar with developing their units around ELA or Math, with science on the sidelines. Some other difficulties the team of teachers faced included attrition (Social Studies and Math teachers dropped out) and the team faced noncooperation from the administration. Undoubtedly, this increased the demands of time and planning on the part of teachers, TD and AM. 
AM: "If they (students) are working a collaborative effort on something, they tend to help each other a lot more."

AM went on to describe the remarkable difference in students' learning behavior with an integrated approach. The teachers adapted multiple approaches to help make science interesting among $8^{\text {th }}$ grade students. Peer tutoring was one of them. Apparently, both teachers had been in touch with research literature on learning/teaching adolescents. There was a clear sense of enthusiasm among students to carry out the intervention, encouraged by peer-oriented relationships. This gave rise to a community of (scientific) investigators. This also shows that the intervention was implemented with a student-centered approach.

7.4 RQ2. What were the characteristics of the emergent curricular model?

TD: "So, you know all these little things that they can do- it really helps them see and understand science."

Evidently, as TD perceived, the intervention did not merely bring about a change or another exciting activity for students, but actually influenced students' perception of science as a subject. Researchers in science education have noted that positive changes in students' perceptions of science by building experiences, helped them see the role of science in their lives, which may well be considered a leap in terms of students' affective orientation towards science (Storksdieck, 2002). It is a critical step that prompts a paradigm shift in students, uncovering their everyday, unnoticed, unconscious relationship with science, highlighting the crucial role of science in their lives.

TD: "Learning is fun and easy....once they have that mentality, it's the idea that they can do it! It gives them a sense of pride, but also self-esteem."

A deeper perception seemed to play a role in students believing that they were capable of learning and doing well in science. Researchers have repeatedly found that students' perception towards science modulates their attitude towards science in multiple and significant ways (Furlong \& Biggart, 1999). Through such processes, the science classroom can become a zone of empowerment and building identity when students are valued for their ability to participate in, critique or contribute (Roth \& Calabrese Barton, 2004).

TD: “...discuss and let them reflect in their journals, after we go out there....”

TD reinforced that students were not passive receivers of knowledge, but actively and collaboratively constructed their understanding of the different concepts involved in the intervention through classroom discussions.

AM: "We...tried to develop or bring in the cross-curricular unit, and the unit (the intervention) is the way to break that pattern."

AM mentioned the traditional separation of content into isolated packets of knowledge while discussing the possible reason(s) for students being unable to make critical connections among content areas. Introducing a cross-curricular approach she thought was an ideal way to allow students to think along the lines of rich, interpretive thinking recognizing the 
interconnected nature of science or any other content area.

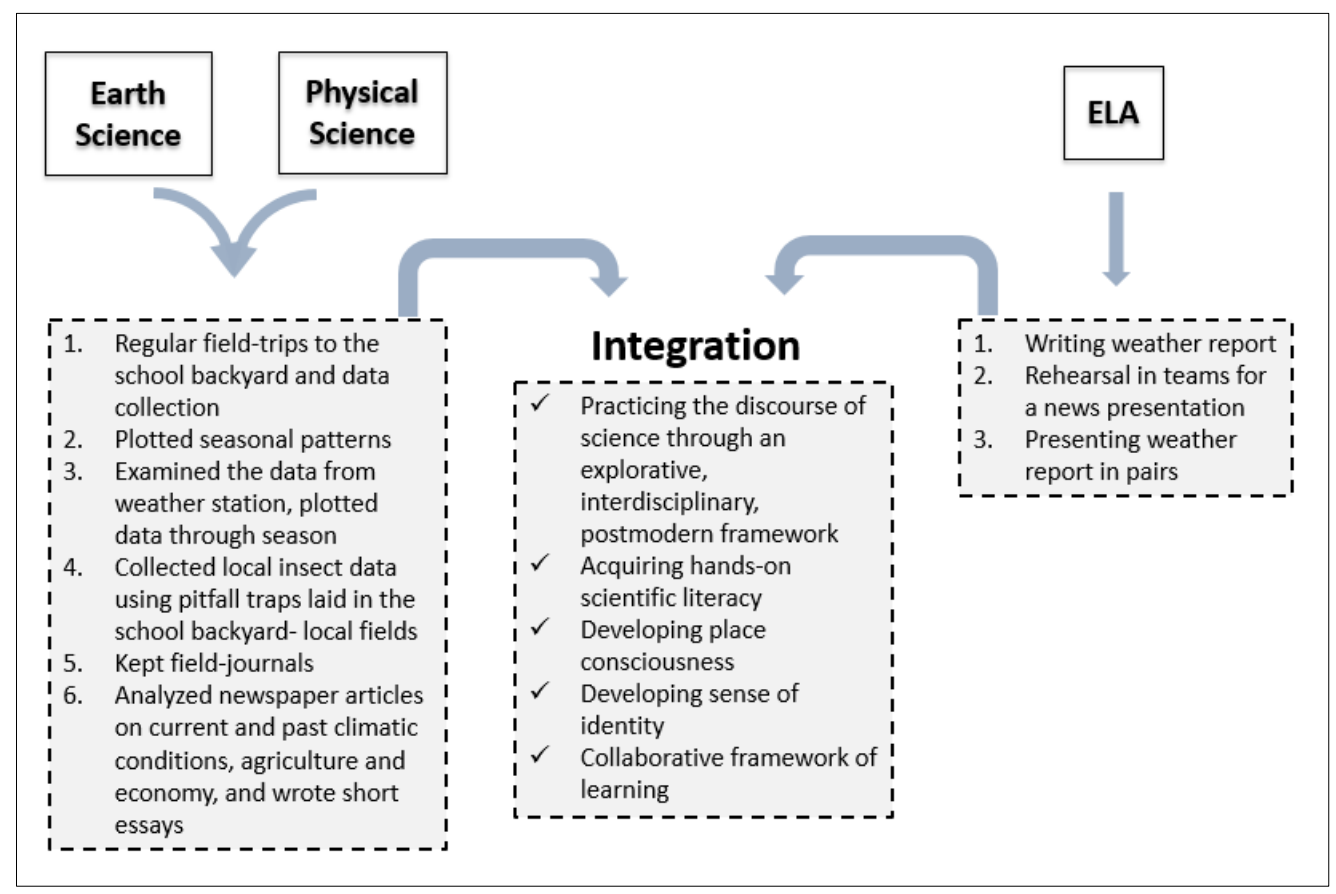

Figure1. Emergent curricular model as a result of implementation of the intervention

AM: "We had to make sure that what we were doing, as far as this project, went along with where we were supposed to be doing (it) especially for ELA, to make it cross over into what we were supposed to be teaching for Common Core.... It (ELA) is extremely scripted."

As shown above, Figure 1 summarizes the emergent curricular model as a result of implementation of the intervention. Implementing the intervention also meant that both teachers, and especially AM had to go through the scope and sequence and kept pace with that along with the Common Core standards and challenge the separate treatment of content.

This was no easy task for the teachers who were not familiar with interdisciplinary teaching.

\section{Discussion}

\subsection{Students (re)conceptualizing the content through post-modern learning}

The design of the intervention was such that it included all students and allowed their perspectives to develop. Curriculum experts and researchers have suggested that more than the 'what' of knowing/learning, being clear and well rooted about the 'why' of learning is significant. In order to produce meaningful engagement, democratic classroom practice in terms of access to the rationale and context, as well as opportunity, is considered indispensable (Roth \& Calabrese Barton, 2004). In this case, clearly discussion took the center-stage and students had a say in what they wanted to do. The value of the intervention seemed rooted in the fact that students and their teachers together generated the content, based on field experiences, which they reflected upon in both Science and ELA classrooms. 
That is the kind of science that is interdisciplinary, personally relevant and welcomes all students to participate. From a wider perspective, diverse space for interaction helps deconstruct gender or racial privileges and motivates diverse students, obviating institutional hegemony or hindrances (Ellsworth, 2005).

Post-modern learning is about constructing new models, and understandings of the world.

Adopting the post-modern approach to teaching science in schools (Littledyke, 2008) includes both cognitive and affective features of learning. Cognitive features include educating students in the methods and ideas of science so that they can use science to interpret and understand the world; assisting students to create meaningful personal frameworks; critically analyzing ideas and their applications in science along with their social and environmental implications. Affective features include fostering a sense of interest, enjoyment and excitement; nurturing beauty, respect and reverence for nature and other living beings, including humans. Overall, in this study it seemed that 'doing' science and articulating it collaboratively helped students enjoy the content as opposed to the abstraction and alienation sometimes students feel from a mechanistic treatment of science/ELA. Indeed, drawing on focus-group discussions, some students were deeply affected by the experience and showed very positive attitudes and new learned behaviors. As was noted in both teachers' classrooms, students took charge of the processes in the intervention and they collaborated to help each other out. Through participative learning, the agency of action was shifted from the teacher (center of power) to the empowered students. As active agents of learning, students seemed to be exploring and rebuilding their identities (Roth \& Calabrese Barton, 2004). These middle school students, who were still in the process of negotiating their identity, were able to work successfully on the intervention and show their work as scientists to their parents. This indicated a very positive attitude not only towards Science, but towards the process of learning itself.

William Doll (1993) defined the post-modern framework as learning to liberate (free it) rather than to hit the bull's eye (kill it). This also means that by embarking on the journey of learning, students are not looking for or memorizing the one correct answer (the bull's eye) but are embarking on a journey to freely define a concept as related to their experience. Learning science through an open framework, as Lyotard conceptualized, is a process-oriented discourse, as in the cultural process of learning (Zembylas, 2008). Essentially, constructive postmodernism encourages a critical look at how science is practiced or constructed, without diminishing its value through constraints. In this case, science was aligned with other discipline/s and shone light on the reality that it works in combination with other content areas, rather than staying aloof as is commonly conceptualized through the hegemonic notion of unapproachable laboratory science. In the process, the teachers not only used science as a tool to overcome prescribed content boundaries but used it reflexively including in discussions that the real nature of science is tentative rather than unquestioned truth. This was a step towards not only enlightenment (i.e., becoming knowledgeable) but empowerment in students' day to day, real lives. 


\subsection{Pedagogical approach of the teachers}

Also, Dewey's vision of curriculum included the active construction of learning, which is in alignment with Currere (post-modern curricular journey) and encourages beginning a discourse with individual experiences and moving towards broader perspective. It is a way of viewing the tree and then the forest; a two-way street between individual and the collective, broader and abstract (Pinar, 1975). As noted, building experiences helps students see the role of science in their lives, which is described as critical towards a paradigm shift in students, uncovering their unnoticed relation with science, thus highlighting the crucial role of science in their lives (Storksdieck, Jones, Falk, \& Alpert, 2002). Clearly the teachers led a struggle through this interdisciplinary treatment of content to break commonly held barriers among disciplines (even among disciplines of science). They overcame challenges in their own ways. In their disciplinary areas, teachers confronted the notion of academic isolation; for instance, they built experiences as opposed to using only prescribed/available resources that treat science as an isolated subject rather than with shared understandings. It was evident that the administration was not supportive of bringing in innovation (perceived as added work), for a subject like science which was not considered critical, judged by the mandates of standardized state testing. Moreover, treating science as a core content area and orienting other content areas around it even for a short time was not something the administration was open to or had experienced earlier. The teachers, while not having taken an interdisciplinary approach surrounding science earlier as well, took the challenge readily. While the science teacher came directly under the scrutiny of the Principal, the ELA teacher integrated the interdisciplinary content into the scripted scope and sequence (presented as prescribed curriculum) within the largely inflexible timeline, all the while staying accountable. However, the asset they built from this effort was not only for these students but also for the future classes. It also opened up new ways of thinking and praxis for their colleagues and the school. The researcher learned through feedback discussion (participant validation) with the teachers since the project that after the success of the project, the teachers have been involved in other projects that supplement and enrich their classroom curricula. It is notable that the role of the teacher is especially critical at the middle school since students' affinity towards learning science reaches a critical point at this stage (Owens, 2013).

\subsection{Coming to terms with the context}

The current interpretation of high-stakes testing has led to preoccupation of schools with raising test scores (Popham, 2010). A classroom becomes a place for drills rather than a learning environment where curriculum is generated. Many students thus disengage themselves from the experience of schooling (Dei, Mazzuca, McIsaac, \& Zine, 1997). Assessment through standardized testing and practice for testing often are given the highest importance within a school environment, which can create a lot of pressure on teachers and students, instead of allowing relationship-building with the content (Booher-Jennings, 2005). The intervention presented teachers with ample opportunities for formative assessment and rather than interpreting it narrowly as a drilling tool for data collection (yet another test), teachers utilized it to integrate innovation into the curriculum. Ms. AM thought standardized testing was like a blind instrument, since it did not take into consideration who the students 
were and their background realities. Also, using students' standardized test scores for teacher evaluation, can have a negative influence on teachers' sense of efficacy, as well as affect students' motivation adversely (Firestone \& Pennell, 1993). From a post-modern perspective, it signifies training students to hit the bull's eye (one pre-determined, correct answer) rather than freeing them to generate and develop their intellectual sophistication on the content, as Doll (1993) contends.

Contrary to the popular notion of top-down approach, the current times of globally connected while geographically distant geopolitical realities demand ways around institutional hegemonies (Slattery, 2006). Teaching and learning through a praxis-oriented, integrated approach is compatible with real world scenarios and much needed in preparing students for not only immediate future (grade level exam/LEAP/iLEAP, ACT in high school, and college readiness) but also for long-term gains (ex., life-skills). In this study, through fieldwork, students played the role of critically thinking participants. Teachers in the study clearly pointed out that students were not given ample opportunity to practice critical thinking since their elementary schooling, which made it hard for them to think critically in abstraction by middle school. They were not encouraged to build a relationship with the content and learn through situated praxis early on. This is where the notion of reconceptualized curriculum came into play. Reflection and conscious experience through the project seemed to help students see themselves in the process of learning. Institutional metanarratives often do not include individual students and their perspectives (Lyotard, 1993). This is most likely to be true for students from minority backgrounds for whom, institutions fail to engage in developing a positive attitude towards the subject matter, through a hegemonic treatment of the content representing culturally dominant groups and unquestioned norms.

\section{Conclusion}

Lack of awareness about the nature of science and its importance clubbed with opposition to innovation (thus risk-taking) can be a huge deterrent for teachers to implement a reconceptualized curricular practice. As was noted by Ms. AM, the so called (given) curriculum was a huge obstacle. The issues were multifarious, including the volume of content, the time given for (un)covering the topics, the sequence of the content, as was also the sequence of disconnected units, and prescription on how the content is to be taught. From the post-modern perspective, relations refer to a rich matrix of complex, layered understandings, and refers to the larger context in which the curriculum is situated (Whitehead, 1967). As was noted in the study, a lot happened during teacher-student interactions as well as through interactions with the content in terms of hands-on learning. Thus, using the intervention as an instrument, and an instance for a praxis-oriented, integrated approach it seemed the teachers and their students established meaningful connections between their lives and the content and thus achieved what seemed like an insurmountable goal in the beginning.

\section{Acknowledgements}

I would like to thank the teachers for their steadfast devotion to the students and the profession of teaching as well as for allowing me to witness the wonderful, shared journey of teaching, learning and watching students grow into investigators. 


\section{1) Macrothink}

Journal of Studies in Education

ISSN 2162-6952

2018, Vol. 8, No. 2

\section{References}

Belanger, S., \& Peters, S. (2008). Investigating adolescents' science stereotypes and their relationship to attitude toward science and career aspirations. Science Stereotypes.

Betts, F. (1992). How systems thinking applies to education. Educational Leadership, 50(3), $38-41$.

Blank, R., Langesen, D., \& Petermann, A. (2007). State Indicators of Science and Mathematics. Washington, DC: Council of Chief State School Officers.

Booher-Jennings, J. (2005). Below the bubble: "Educational triage" and the Texas accountability system. American Educational Research Journal, 42(2), 231-268. https://doi.org/10.3102/00028312042002231

Branch, G. (2013). Defending Science Education: Climate as a second front for biologists. BioScience, 63(9). https://doi.org/10.1093/bioscience/63.9.717

Dei, G. S. F., Mazzuca, J., McIsaac, E., \& Zine, J. (1997). Reconstructing Drop-out: A critical ethnography of the dynamics of black student's disengagement from school. Toronto, Canada: University of Toronto Press. https://doi.org/10.3138/9781442679078

Dewey, J. (1915). The school and society (Rev. ed.). Chicago, IL: University of Chicago Press.

Doll, W. E., Jr. (1993). A post-modern perspective on curriculum. New York, NY: Teachers College Press, Columbia University. https://doi.org/10.5860/CHOICE.30-6295

Duran, F., Hepburn, K., Irvine, M., Kaufmann, R., Anthony, B., Horen, N., \& Perry, D. (2009). What Works: A Study of Effective Early Childhood Mental Health Consultation Programs. Washington, DC: Georgetown University Center for Child and Human Development.

Ellsworth, E. (2005). Places of learning: Media, architecture, pedagogy. New York, NY: Routledge.

Esteva, G., \& Prakash, M. S. (1998). Grassroots Postmodernism: Remaking the Soil of Cultures. London: Zed Books.

Falk, J. H. (2002). The contribution of free-choice learning to public understanding of science.Interciencia, 27(2), 62-65.

Falk, J.H., \& Coulson, D. (2001). Preliminary Analysis of Second Telephone Survey: California Science Center LASER Project. Technical Report. Annapolis, MD: Institute for Learning Innovation.

Falk, J. H., \& Dierking, L. D. (2002). Lessons without limit: How free-choice learning is transforming education. Walnut Creek, CA: AltaMira Press. https://doi.org/10.1590/S0104-59702005000400008 
Firestone, W. A. (2014). Teacher evaluation policy and conflicting theories of motivation.Educational Researcher, 43(2), 100-107. https://doi.org/10.3102/0013189X14521864

Firestone, W. A., \& Pennell, J.R. (1993). Teacher commitment, working conditions, and differential incentive policies. Review of Educational Research, 63(4), 489- 525. https://doi.org/10.3102/00346543063004489

Freedman, M. P. (1997). Relationship among laboratory instruction, attitude toward science, and achievement in science knowledge.Journal of Research in Science Teaching, 34(4), 343-357.

https://doi.org/10.1002/(SICI)1098-2736(199704)34:4<343::AID-TEA5>3.0.CO;2-R

Friere, P. (1970). Pedagogy of the oppressed. New York, NY: The Continuum International Publishing Group Inc. https://doi.org/10.1007/978-1-4614-5583-7_610

Furlong, A., \& Biggart, A. (1999). Framing Choices: A longitudinal study of occupational aspirations among 13 to 16 year-olds. Journal of Education and Work, 12(1), 21-36. https://doi.org/10.1080/1363908990120102

Gruenewald, D. A., Smith, G. A. (2008). Place-Based Education in the global age. New York, NY: Routledge. https://doi.org/10.4324/9781315769844

Goodnough, K., \& Cashion, M. (2006). Exploring problem based learning in the context of high school science: Design and implementation issues. School, Science and Mathematics, 106, 280-295. https://doi.org/10.1111/j.1949-8594.2006.tb17919.x

Guba, E. G., \& Lincoln, Y. S. (1989). Fourth generation evaluation. Newbury Park, CA: Sage. https://doi.org/10.1177/109821409201300308

Hofstein, A., \& Rosenfeld, S. (1996). Bridging the gap between formal and informal science learning. Studies in Science Education, 28(1), 87-112. https://doi.org/10.1080/03057269608560085

Knapp, C. (2008). Place-based curricular and pedagogical models. New York, NY: Taylor \& Francis Group.

Lieberman, G., \& Hoody, L. (1998). Executive summary: Closing the achievement gap: Using the environment as an integrating context for learning. SEER REPORT. San Diego, CA: State Education and Environment Roundtable.

Lim, M., \& Barton, A. C. (2006). Science learning and a sense of place in a urban middle school. Cultural Studies of Science Education, 1(1), 107-142. https://doi.org/10.1007/s11422-005-9002-9 
Littledyke, M. (2008). Science education for environmental awareness: approaches to integrating cognitive and affective domains. Environmental Education Research, 14(1), 1-17. https://doi.org/10.1080/13504620701843301

Lyotard, J. F. (1993). The Postmodern Condition: A Report on Knowledge Translation from the French by Geoff Bennington and Brian Massumi. Minneapolis: University of Minnesota Press.

McCarthy, C. B. (2005). Effects of thematic-based, hands-on science teaching versus a textbook approach for students with disabilities. Journal of Research in Science Teaching, 42(3), 245-263. https://doi.org/10.1002/tea.20057

McComas, W. F. (2006). Science Teaching beyond the Classroom.Science Teacher, 73(1), 26-30.

McLaren, P. L., \& Giroux, H. A. (1990). Critical pedagogy and rural education: A challenge from Poland. Peabody Journal of Education, 67(4), 154-165. https://doi.org/10.1080/01619569009538705

Miles, M. B., \& Huberman, A. M. (1994). Qualitative Data Analysis: An Expanded Sourcebook. Thousand Oaks, California: Sage Publications.

Miller-Rushing, A., Primack, R., \& Bonney, R. (2012). The history of public participation in ecological research. Frontiers in Ecology and Environment, 10(6), 285-290. https://doi.org/10.1890/110278

National Governor's Association. (2008). Benchmarking for success: Ensuring U.S. students receive world-class education. Washington, DC: National Governor's Association, Council of Chief State School Officers, and Achieve, Inc.

National Research Council. (1996). National Science Education Standards. Washington, DC: National Academy Press.

National Research Council. (2012). A framework for K-12 Science Education- Practices, crosscutting concepts, and core ideas. Washington, DC: The National Academies Press.

National Science Foundation. Released November 8, 2008. Discovery: Real Science for Younger Scientists Retrieved from http://www.nsf.gov/discoveries/disc_summ.jsp ?org= DRL\&cntn_id=100732\&preview=falseon Jan 14, 2015.

Organization for Economic Co-operation and Development. (OECD). (2015). PISA 2015: PISA results in focus. Paris: OECD.

Owens, C. D. (2013). Exploring the relationship between compass student learning measures and high school math teacher's sense of efficacy in two Northeast Louisiana school districts (Doctoral dissertation). Retrieved from http://gradworks.umi.com/35/78/3578811.html (3578811)

Parker, V., \& Gerber, B. (2000). Effects of a Science Intervention Program on Middle-Grade Student Achievement and Attitudes.School Science and Mathematics, 100(5), 236-242. https://doi.org/10.1111/j.1949-8594.2000.tb17263.x 
Piaget, J. (1954). The construction of reality in the child. New York, NY: Basic Books. https://doi.org/10.1037/11168-000

Pinar, W. F. (1975). Currere: Toward reconceptualization.In Pinar, W. (Ed.), Curriculum theorizing, 396-414. Berkeley, CA: McCutchan.

Pope, M., \& Gilbert, J. (1983). Personal experience and the construction of knowledge in science. Science education, 67(2), 193-204. https://doi.org/10.1002/sce.3730670208

Popham, J. W. (2010). Classroom Assessment: What teachers need to know. New Jersey: Pearson. https://doi.org/10.1177/073428290402200106

Ricks, M. M. (2006). A study of the impact of an informal science education program on middle school students' science knowledge, science attitude, STEM high school and college course selections, and career decisions. (Doctoral dissertation) Retrieved from https:// www.lib.utexas.edu/etd/d/2006/ricksm81757/ricksm81757.pdf on March 1, 2015.

Romance, N. R., \& Vitale, M. R. (2001). Implementing an in-depth expanded science model in elementary schools: Multi-year findings, research issues, and policy implications. International Journal of Science Education, 23(4), 373-404. https://doi.org/10.1080/09500690116738

Roth, W. M., \& Calabrese Barton, A. (2004). Rethinking scientific literacy. New York, NY: RoutledgeFalmer. https://doi.org/10.4324/9780203463918

Slattery, P. (2006). Curriculum development in the Postmodern Era. New York, NY: Routledge Publishers. https://doi.org/10.4324/9780203826140

Sobel, D. (2004). Place-Based Education: Connecting Classrooms and Communities. Massachusetts: Nature Literacy Series.

Sobel, D. (2008). Childhood and nature: Design principles for educators. Maine: Stenhouse Publishers.

Storksdieck, M., Jones, M. C., Falk, J. H., \& Alpert, C. L. (2002). Public Understanding of Science: A Literature Review. Museum of Science, Boston, MA: Institute for Learning Innovation.

Van Maanen, M. (1997). From meaning to method. Qualitative health research, 7(3), 345-369. https://doi.org/10.1177/104973239700700303

Webster-Wright, A. (2009). Reframing Professional Development through understanding authentic professional learning. Review of Educational Research, 79(2), 702-739. https://doi.org/10.3102/0034654308330970

Whitehead, A. N. (1967a). The aims of education. New York, NY: Free Press. https://doi.org/10.4324/9780203003985

Wyss, V. L., Dolenc, N., Kong, X., \& Tai, R.H. (2013). Time on Text and Science Achievement for High School Biology Students. American Secondary Education, 41(2). 


\section{Macrothink}

Journal of Studies in Education ISSN 2162-6952 2018, Vol. 8, No. 2

Zembylas, M. (2008). The Unbearable Lightness of Representing 'Reality' in Science Education: A response to Schulz. Educational Philosophy and Theory, 40(4). https://doi.org/10.1111/j.1469-5812.2007.00360.x 